\title{
COMPARISON OF SOME BIOCHEMICAL VARIABLES DURING KICKBOXING COMPETITIONS
}

\author{
Mustafa Karadağ ${ }^{1 i}$, \\ Naci Ömer Alayunt ${ }^{2}$, \\ Kürşat Kargün ${ }^{3}$, \\ Yüksel Savucu', \\ Ercan Gür ${ }^{1}$, \\ Alper Karada $\breve{g}^{4}$, \\ Oktay K1zar ${ }^{5}$ \\ ${ }^{1}$ Firat University, \\ Faculty of Sport Sciences, \\ Elazığ, Turkey \\ ${ }^{2}$ University of Siirt, \\ Faculty of Medicine, \\ Department of Medical Biochemistry, \\ Siirt, Turkey \\ ${ }^{3}$ Firat University, \\ Faculty of Health Sciences, \\ Elazı̆̆, Turkey \\ ${ }^{4}$ Muş Alparslan University, \\ Faculty of Sport Sciences, \\ Muş, Turkey \\ ${ }^{5}$ Bingol University, \\ High School of Physical Education and Sports, \\ Bingol, Turkey
}

\begin{abstract}
:
Background: Kickboxing is a high-intensity, intermittent combat sport, which is characterized by short-term complex abilities and tactical key movements. In this study, it was aimed to investigate the factors related to variability in potential biochemical parameters and competition behavior of high-level kickboxing athletes. Methods: Blood samples of athletes, which were obtained pre- and post-maximal competition applied in accordance with the period, were investigated. In the study, a total of 50 athletes, which consisted of 39 male and 11 female amateur athletes with a mean age of $20.08 \pm 6.33$. Results: Significant differences were determined in the Body Mass Index (BMI) values between females and males. It was determined that athletes' Aspartate Aminotransferase (AST), Alanine Transaminase (ALT), Total Oxidant Level (TOL) and Malondialdehyde
\end{abstract}

i Correspondence: email kkargun@firat.edu.tr 
(MDA) values were significantly increased pre- and post-competition while it was determined that Total Antioxidant Level (TAL) were significantly decreased $(p<0.05)$. According to the findings, it was observed that there were statistically significant differences between serum antioxidant, oxidant and liver enzymes of amateur level kickboxing athletes pre- and post-competition. Conclusion: In conclusion, considering the effects of effects of strikes received on the chest area and the effects of the liver, which is located in the intersection of all metabolic pathways, on muscle, increases in liver enzymes is an ordinary situation. It was finally observed that the strikes received caused increases in liver enzyme levels while decreased TAL and increased TOL levels were encountered based on antioxidant enzyme levels spent for removing the free radicals formed as a result of heavy exercise.

Keywords: kickboxing, malondialdehyde (MDA), total antioxidant level (TAL), total oxidant level (TOL), aspartate aminotransferase (AST), alanine transaminase (ALT)

\section{Introduction}

Kickboxing is a combat sport, which is combined from Karate, Thai Boxing and Boxing sports, usually practiced with an aim of defense, prioritizing kicks and punches, and based on certain rules $(1,2)$. By virtue of individual defense, improving muscle power and endurance, and keeping the body in shape, the interest in kickboxing has gradually increased worldwide (3). Proportional to the rate of the intensity and period of physical activity, it can cause more radical scavenger formation by increasing metabolic processes and oxygen consumption. The potential damage of free radicals in exercise depends on the intensity of the exercise (4). Many researchers have investigated the effects of acute or long-term various exercise programs on biochemical parameters $(5,6)$. The oxygen requirement of tissues increases with sportive activities. In such circumstances, the oxygen that is taken into the body also needs to increase (7). In parallel with the increased amount of oxygen with the exercise, reactive oxygen species in organisms are expected to increase as well (8). These products, which emerge as a natural result of physiological activities in humans and animals (9), are free radicals, which are defined as molecules or molecular particles that contain one or more than one unpaired electron in bonds $(7,10)$. Free radicals are generally species of reactive oxygen and reactive nitrogen. Free radicals are known to be effective on membrane lipids (lipid peroxidation), proteins, carbohydrates along with nucleic acids and Deoksiribo Nükleik Asit (DNA). Oxidative DNA damage is an inevitable result of cellular metabolism, which has a tendency to increase in its levels depending on the toxic factors. Each piece of DNA is an easy target for the attacks of free oxygen radicals $(11,12)$. In organisms, there are defense mechanisms, which are called the antioxidant defense system, to prevent the formation of reactive oxygen species and the damages caused by these. The duty of the antioxidant effect mechanisms is to prevent the formation of free radicals and the neutralization of the free radicals formed (10). 
Use of oxygen in releasing energy from organic molecules by aerobic organisms exposes these organisms to the harmful effects of toxic oxygen product. Interestingly, these toxic oxygen products result from the physiologic and metabolic process, which are vital for cells (13). In the evolutional process, a protective system, which is called "Antioxidant Defense System", was developed to neutralize reactive oxygen metabolites (14). The duty of this system is to protect the cell from harmful effects of free radicals, which are formed during the partial reduction of oxygen. Normally, organisms have a sensitive balance that eliminates the harmful effects between the reactive oxygen species formed in organisms and antioxidant activity (15). It is believed that lipid peroxidation, which is originated from the reaction of free radicals with lipids, is common in the organism. When lipid peroxides $(\mathrm{LOOH})$ are broken down, aldehydes, most of which are biologically active, are formed. The final products of lipid peroxidation are aldehydes (Malondialdehyde-MDA), 4- hydroxynonenal) and hydrocarbon gases (ethane and pentane). The sensitivities of biological membranes to peroxidation are different from each other. Mitochondrial and microsomal membranes are especially sensitive to free radicals due to high contents of PUFA in their phospholipids. Degradation of lysosomal membranes causes the release of hydrolytic enzymes, which mediates intracellular digestion. These compounds are either metabolized in the cellular level or diffused from their initial area of influence, spreading the damage to the other parts of the cell. In the peroxidation of three or more double bonded fatty acids, MDA is formed. MDA is manifested in blood and urine and it has a good correlation with the degree of lipid peroxidation while it is not a specific or quantitative indicator of fatty acid oxidation. Therefore, MDA measurement in biological material is used as an indicator of lipid peroxide level. Non-enzymatic lipid peroxidation is a very harmful chain reaction. It directly damages membrane structure and indirectly damages cell components by reactive aldehydes it produces. Therefore, it causes tissue damage and many diseases.

In this study, it was aimed to investigate the effects of exercise on oxidative stress and antioxidant system regarding removing or reactive oxygen species, which can result from liver enzyme activity following exercise and depending oxygen consumption that increases in exercise, in pre- and post-competition in high-level kickboxing athletes.

\section{Materials and Methods}

\subsection{Participants}

A total of 50 amateur athletes, 39 males and 11 females, voluntarily participated in the study. The physical characteristics of the participants were presented in Table 1 . The biochemical variables of athletes throughout the kickboxing competitions were presented in Table 2 and Figures.

\subsection{Experimental Design}

The matches were played according to International Kickboxing Federation rules (light contact) but included a slightly longer recovery time between rounds. The participants were informed about the purpose and content of the study and the necessary permissions 
were taken. Additionally, the required written and verbal explanations about study and measurements were made and the individuals who agreed to participate in the study signed the "Informed Voluntary Consent Form".

For the pre- and post-competition biochemical evaluations of athletes, whose mean age is $20.08 \pm 6.33$, the blood samples were transferred to straight gel biochemistry tubes. These were centrifuged at 4000 RPM for 5-10 minutes, obtaining their serums and plasmas, respectively. These serums and plasmas were transferred to Eppendorf tubes and stored at $-20{ }^{\circ} \mathrm{C}$ until the day of evaluation.

The blood samples, which were transferred to straight gel biochemistry tubes, were thawed on the day of evaluation and Aspartate Aminotransferase (AST) and Alanine Transaminase (ALT) levels were spectrophotometrically measured with suitable kits while Total Antioxidant Level (TAL) and Total Oxidant Level (TOL) levels were colorimetrically measured with suitable kits by using Siemens Advia 2400 autoanalyzer device. Serum total antioxidant (TAL) was measured by using capacity kit with the colorimetric method in the autoanalyzer. By using ASSAY KIT Catalog no: RL0017 LOT: RL024, the measurement was conducted at $660 \mathrm{~nm}$ with the unit of mmol Trolox. Equiv/L. Serum total oxidant was measured by using the capacity kit with the colorimetric method in the autoanalyzer. By using ASSAY KIT Catalog no: RL0024 LOT: RL026, the measurement was conducted at $530 \mathrm{~nm}$ with the unit of $\mu \mathrm{mol} \mathrm{H} 2 \mathrm{O} 2$ Equiv./L.

\subsection{MDA Assay}

One of the final products of free radicals is MDA by subjecting unsaturated fatty acids to peroxidation. MDA reacts with thiobarbituric acid (TBA) and forms a colored compound. Lipid peroxidation assay was conducted by measuring the absorbance of this colored compound at 532 and $600 \mathrm{~nm}$ wavelengths in the spectrophotometer (Shimadzu 1700 UV/VIS).

\section{Results}

The demographical information of the athletes was presented in Table 1. It was determined that pre- and post-competition results in athletes' parameters measured constituted significant differences (Table 2). While significant increases were observed in AST, ALT, TOC, MDA levels post-competition, significant decreases were observed in Total Antioxidant Capacity (TAC) levels.

Table 1: Demographical Information of Athletes

\begin{tabular}{|l|c|c|c|}
\hline & Male & Female & --P-- \\
\hline Age & \multicolumn{2}{|c|}{$20,08 \pm 6,33$} & \\
\hline BMI, $\mathrm{kg} / \mathrm{m}^{2}$ & $20,86 \pm 3,35$ & $17,99 \pm 1,74$ & 0,023 \\
\hline
\end{tabular}

The data were presented as means \pm standard deviation. The comparison between genders was conducted by Mann Whitney U test $(\mathrm{p}<0.05)$. 

COMPARISON OF SOME BIOCHEMICAL VARIABLES DURING KICKBOXING COMPETITIONS

Table 2: Pre- and post-competition biochemical changes in athletes

\begin{tabular}{|l|c|c|c|}
\hline Items & Before & After & P value \\
\hline AST, $\mathrm{U} / \mathrm{L}$ & $18.90 \pm 3.13$ & $26.44 \pm 4.99$ & 0.0001 \\
\hline ALT, $\mathrm{U} / \mathrm{L}$ & $12.96 \pm 1.92$ & $20.94 \pm 3.45$ & 0.0001 \\
\hline TAC, $\mathrm{mmol} . \mathrm{T} . \mathrm{E} / \mathrm{L}$ & $1.72 \pm 0.15$ & $1.49 \pm 0.06$ & 0.0001 \\
\hline $\mathrm{TOC}, \mu \mathrm{mol} . \mathrm{H}_{2} \mathrm{O}_{2} . \mathrm{E} / \mathrm{L}$ & $19.22 \pm 0.33$ & $25.25 \pm 0.91$ & 0.0001 \\
\hline $\mathrm{MDA}, \mathrm{nmol} / \mathrm{ml}$ & $1.35 \pm 0.09$ & $2.14 \pm 0.16$ & 0.0001 \\
\hline
\end{tabular}

\section{Discussion and Conclusion}

Physical activity and exercise habits provide many benefits such as preventing obesity, cardiovascular diseases, diabetes and some certain chronic diseases and maintaining a healthy lifestyle. In addition to these beneficial effects of exercise, it was stated that especially during training and matches of combat sports such as kickboxing, depending on the strikes received on head and neck areas and body, levels of several biochemical damage indicators were increased (17) and acute or intense physical exercise caused increases in reactive oxygen species, resulting in cell damage in tissues (18).

The relationship between exercise and oxidative stress depends on the type of exercise, intensity, time, genetics and lifestyle. A very complex table exists against the damages of determined oxidative stress depending on individual sensitivity (19). Acute exercises increase antioxidant enzyme activity (20) while chronic exercises develop resistance against oxidative stress (21) and reduce the basal level of oxidative damage (20). Furthermore, oxidative stress cause damages in proteins, carbohydrates, fats and DNA. The natural antioxidant systems of the body exhibit activities against free radicals, which are sources of oxidative stress, and prevent damages to be formed in organisms. This study was conducted with the aim of determining the effects of intense exercise stress formed in athletes' muscles on DNA damage and oxidative stress. In the comparison of exercise and TOL values, the exercise group had a statistically significant increase (Table 2). During the exercise, the increase in aerobic metabolism is a probable cause of oxidative stress (22). Ramel, Wagner and Elmadfa (2004) reported that shortterm exercise caused oxidative stress (23). In the results of studies conducted with humans and experimental animals, it was reported that TOL and TBARS (thiobarbituric acid reactive substances-MDA) values, which are indicators of oxidative stress, were significantly higher $(24,25)$. Scientific studies determined that short-term or acute intense exercises increased oxidative stress (26). Contrary to this study and the general results in the literature, several studies determined that acute exercises did not have an effect on oxidative stress or decreased oxidative stress (27). Inversely proportional to the intensity and time of exercise, studies also reported that there were significant decreases in oxidative stress indicators $(28,29)$. It is believed that these results depend on exercise protocols or differences in measurement methods. In the comparison of TAL values of sedentary and exercise groups, it was observed that there were statistically significant differences and there were decreases with exercise. This decrease is believed to be due to the fact that the total antioxidant capacity is spent in the cellular environment to catch 
free oxygen radicals formed. Therefore, it can be stated that the natural antioxidant system of the body tends to decrease against oxidative stress. In such a condition, it can be stated that we need to support our natural defense system, which makes an effort to destroy free radicals, with necessary vitamins and food supplements, thus, ensure that the antioxidant system is kept in a balanced state.

ALT, AST, ALP and GGT enzyme activities are routine biochemical indicators, which are used to evaluate live damage $(30,31)$. In our study, we observed that ALP, AST, ALT and GGT levels of kickboxing athletes were statistically significantly increased following exercise. It was reported that liver enzyme levels were increased following various exercise programs and sports matches of athletes in many different sports branches. The results reported in the literature demonstrated similarities with the findings of our study (32-35) while several studies reported that liver enzyme levels did not differ $(36,37)$. It is known that increases in exercise intensity and time generally increased ALT and AST levels (38). In endurance sports, liver enzyme values demonstrated differences depending on exercise time. In marathon runner athletes, it was observed that there were increases in GGT and AST values following competitions while it was reported that GGT values decreased 6 hours after the competition and AST values increased even after 24 hours (39).

In conclusion, our study determined parallel results to literature knowledge. Especially after extreme exercise, kickboxing athletes had increased TOL and MDA values originating from oxidative stress as well as increases in liver enzymes. We believe that these are connected to tissue damage following strikes and leaked oxygen radicals. Additionally, we believe that the decrease in TAL values following oxidative stress emerges with the decreases in antioxidant levels used in destroying free radical leakages. Future studies that are more comprehensive and wider are required on this subject.

\title{
Ethical Considerations
}

Ethical issues (including plagiarism, informed consent, misconduct, data fabrication and/or falsification, double publication and/or submission, redundancy, etc.) have been completely observed by the authors.

\section{Acknowledgements}

No funding was received.

\section{Conflict of Interests Statement}

The authors declare that there is no conflict of interests.

\author{
About the Authors \\ Mustafa Karadağ, Associate Professor, Frrat University, Faculty of Sport Sciences, Elazı $\breve{g}$, \\ Turkey.
}

Naci Ömer Alayunt, University of Siirt, Faculty of Medicine, Department of Medical Biochemistry, Siirt, Turkey. 
Kürşat Kargün, Expert searcher, Furat University, Faculty of Health Sciences, Elazı̆̆, Turkey.

Yüksel Savucu, Professor, Firat University, Faculty of Sport Sciences, Elazı $\breve{g}$, Turkey.

Ercan Gür, Professor, Firat University, Faculty of Sport Sciences, Elazı̆̆, Turkey.

Alper Karadağ, Professor, Muş Alparslan University, Faculty of Sport Sciences, Muş, Turkey.

Oktay Kızar, Associate Professor, Bingol University, High School of Physical Education and Sports, Bingol, Turkey.

\section{References}

1. Gartland S, Malik M, Lovell ME (2001). Injury and injury rates in Muay Thai kickboxing. Br J Sports Med, 35:308-313.

2. Aykin A. G (2010). Examination of the Administrative and Financial Structure of the Kick Boxing Federation. Institute of Social Sciences. Department of Sports Management. Master Thesis, Antalya: Akdeniz University.

3. Zazryn TR, Finch CF, McCrory PA (2003). 16 year study of injuries to professional kick boxers in the state of Victoria, Australia. Br J Sports Med;37:448-451.

4. Çolakoglu M, Tiryaki Ş, Moral S (1993). The Effect of Concentration Studies on Reaction Time. Journal of Sport Sciences, (4) 4, 32-47.

5. Tran ZV, Weltman A (1985). Differential effects of exercise on serum lipid and lipoprotein levels seen with changes in body weight: a meta-analysis. JAMA, 254:919-924.

6. La Monte MJ, Durstine JL, Addy CL, et al. (2001). Physical activity, physical fitness, and Framingham 10-year risk score: cross- cultural activity participation study. J Cardiopulm Rehabil; 21:63-70.

7. Günay M, Tamer K, Cicioğlu İ (2006). Sport Physiology and Performance Measurement. Ankara, Gazi Publishing.

8. Urso ML, Clarkson PM (2003). Oxidative stress, exercise andantioxidant supplementation. Toxicology, 189:41-54

9. Dündar Y, Aslan R. (1999). The Role of Vitamins in Oxidant-Antioxidant Equilibrium and Protection. Journal of Animal Husbandry Research, 9(1-2): 32-39.

10. Akkuş İ. (1995). Serbest Radikaller ve Fizyopatolojik Etkileri, Konya, Mimoza Yayınları, 1-75.

11. Cheeseman KH, Slater TF (1993). An introduction to free radical biochemistry. British Medical Bulletin, 49:481-93.

12. Dizdaroglu M, Jaruga P, Birincioglu M, Rodriguez H (2002). Free Radical-induced damage to DNA: mechanisms and measurement. Free Radical Biolog and Medicine, 32:1102-15

13. Yu BP (1993). Modulation of membrane phospholipid fatty acid composition by Age and food restriction. Gerontology, 39: 7-18. 

COMPARISON OF SOME BIOCHEMICAL VARIABLES DURING KICKBOXING COMPETITIONS

14. Hailiwell B, Gutteridge JMC (1986). Oxygen free radicals and iron in relation to biology and medicine: Some problems and concepts. Archives of Biochemistry and Biophysics, 246(2): 501-514.

15. McCord JM (1993). Human disease, free radicals, and the oxidant/antioxidant balance. Clin Biochem, 26: 351-357.

16. Jain S, Mc Vie, R, Duett J, et al. (1989). Erytrocyte Membrane Lipid Peroxidase and Glycolylated Hemoglobin in Diabetes. Diabetes, Vol.38, pp 1539-1543.

17. Callard R, \& Gearing A (1994). The Cytokine Facts Book. Orlando, Academic Press.

18. Çavuşoğlu H (1991). Exercise and blood, Istanbul Medical Faculty 11th Congress Proceedings Book, 249-252.

19. Gill S, Teixeira K, Rama A, Prestes L, Rosado J, Hankey F, Costa, R. J (2015). Circulatory endotoxin concentration and cytokine profile in response to exertional-heat stress during a multi-stage ultra-marathon competition. Exerc Immunol Rev, 21, 114-128.

20. Pingitore A, Pereira Lima G, Mastorci F, et al. (2015). Exercise and Oxidative Stress: Potential Effects of Antioxidant Dietary Strategies in Sports, Nutrition 13. (doi:10.1016/j.nut.2015.02.005).

21. Radak Z, Taylor A W, Ohno H, et al (2001). Adaptation to exercise induced oxidative stress: from muscle to brain. Exercise Immunology Review, 7:90-107.

22. Radak Z, Kaneko T, Tahara S, et al (1999). The effect of exercise training on oxidative damage of lipids, proteins and DNA in rat skeletal muscle: evidence for beneficial outcomes. Free Radical Biology and Medicine, 27:69-74.

23. Leeuwenburgh C, Heinecke JW. (2001). Oxidative stress and antioxidants in exercise. Current Medicinal Chemistry, 8:829-838.

24. Ramel A, Wagner KH, Elmadfa I (2004). Plasma antioxidants and lipid oxidation after submaximal resistance exercise in men. European Journal of Nutrition, 43:26.

25. Radak Z, Asano K, Inoue M, et al. (1995). Superoxide dismutase derivative reduces oxidative damage in skeletal muscle of rats during exhaustive exercise. Journal of Applied Physiology (Bethesta, Md), 79:129-135.

26. Kürkçü R, Çakmak A, Zeyrek D. (2012). The effect of Taekwondo training on oxidative stress in children. Erciyes Medical Journal, 34:7-9.

27. Thirumalai T, Viviyan Therasa S, Elumalai EK, et al. (2011). Intense and exhaustive exercise induce oxidative stress in skeletal muscle, Asian Pacific Journal of Tropical Disease, 63-66.

28. Aksu İ, Topcu A, Çamsari UM, Acikgöz O (2009). Effect of acute and chronic exercise on oxidant- antioxidant equilibrium in rat hippocampus, prefrontal cortex and striatum. Neuroscience Letters, 452:281-285.

29. Düzova H, Emre MH, Karakoç Y, et al (2006). Effect of medium and high treadmill exercise on muscle and erythrocyte oxidant/antioxidant system of rats. Journal of Inonu University Medical Faculty, 13:1- 5. 
30. Sarıtaş N, Uyanık F, Hamucu Z, et al (2011). Effects of acute twelve two minute run test on oxidative stress and antioxidant enzyme activities. African Journal of Pharmacy and Pharmacology, 5:1218-1222.

31. Pratt DS, Kaplan MM (2000). Evaluation of abnormal liver enzyme results in asymptomatic patients. New Engl J Med; 342:1266-1271.

32. Şentürk H, Canbakan B, Hatemi İ (2004). Clinical approach to liver enzyme elevations. Istanbul University, Cerrahpaşa Medical Faculty, Continuing Medical Education Activities, Gastroenterology Clinical Approach Symposium Series, İstanbul; 38:9-13.

33. Lenaerts AJ, Johnson CM, Marrieta KS, et al. (2005). Significant increases in the levels of liver enzymes in mice treated with anti-tuberculosis drugs, Int J Antimicrob Agents; 26:152-158.

34. Nathwani RA, Pais S, Reynolds TB, Kaplowitz N (2005). Serum alanine aminotransferase in skeletal muscle diseases. Hepatology;41:380-382.

35. Saha B, Maity C (2002Alteration of serum enzymes in primary hypothyroidism. Clin Chem Lab Med; 40:609-611.

36. Haralambie G (1973). Neuromuscular irritability and serum creatine phosphate kinase in athletes in training. Int Z Angew Physiol; 31:279-288.

37. Marcos Bürger-Mendonça, Bielavsky M, Fernanda C, Barbosa R (2008). Liver overload in Brazilian triathletes after halfironman competition is related muscle fatigue. Ann Hepatol; 7:245-248.

38. Lippi G, Schena F, Montagnana M, et al. (2011). Significant variation of traditional markers of liver injury after a halfmarathon run, European Journal of Internal Medicine; 22:36-38.

39. Rosmarın MN, Beard MJ, Robbıns SW (1993). Serum enzyme activities in individuals with different levels of physical fitness. J Sports Med Physical Fitness; 33:252-257.

40. Çakmakçı E, Pulur A (2008). The effects of national team camp period on some biochemical parameters in female Taekwondociler. S. U. PES, Science Journal, 10:39-47. 
Mustafa Karadağ, Naci Ömer Alayunt, Kürşat Kargün, Yüksel Savucu, Ercan Gür, Alper Karadağ, Oktay Kızar COMPARISON OF SOME BIOCHEMICAL VARIABLES DURING KICKBOXING COMPETITIONS

Creative Commons licensing terms

Authors will retain the copyright of their published articles agreeing that a Creative Commons Attribution 4.0 International License (CC BY 4.0) terms wil be applied to their work. Under the terms of this license, no permission is required from the author(s) or publisher for members of the community to copy, distribute, transmit or adapt the article content, providing a proper, prominent and unambiguous attribution to the authors in a manner that makes clear that the materials are being reused under permission of a Creative Commons License. Views, opinions and conclusions expressed in this research article are views, opinions and conclusions of the author(s). Open Access Publishing Group and European Journal of Physical Education and Sport Science shall not be responsible or answerable for any loss, damage or liability caused in relation to/arising out of conflict of interests, copyright violations and inappropriate or inaccurate use of any kind content related or integrated on the research work. All the published works are meeting the Open Access Publishing requirements and can be freely accessed, shared, modified, distributed and used in educational, commercial and non-commercial purposes under a Creative Commons attribution 4.0 International License (CC BY 4.0). 